\title{
Modelo de apoio à decisão multicritério para terceirização de atividades produtivas baseado no método SMARTS
}

\author{
Último de Valois A.B.I.J.C.S.U.Dias \\ Adiel Teixeira de Almeida Universidade Federal de Pernambuco
}

\section{RESUMO}

Este artigo apresenta um modelo decisório para estruturar o dilema entre terceirizar e executar, com recursos próprios, atividades produtivas dentro de uma organização. A decisão de quais atividades devem ser terceirizadas e com quem exige que o decisor analise vários aspectos, como qualidade, custos, credibilidade e outros, além dos aspectos legais que impõem algumas restrições à execução de atividades por terceiros. 0 modelo proposto de apoio à decisão está fundamentado na teoria da utilidade multiatributo, através da técnica SMARTS (Simple Multiattribute Rating Technique using Swings). A aplicação deste modelo mostrou-se uma ferramenta simples e adequada ao problema decisório da terceirização de atividades.

\section{PALAVRAS-CHAVE}

Terceirização, Decisão Multicritério, SMARTS, Modelo de Apoio à Decisão.

\section{Support model for multicriteria decision to outsource productive activities based on SMARTS method}

\begin{abstract}
This article presents a decision model to sctructure the dilemma between outsource and perform, with its own resources, productive activities within an organization. The decision of where and with whom outsource activities requires that the decision maker examine various aspects such as quality, cost, credibility and others, besides the legal aspects that impose some restrictions on the implementation of activities by third parties. The proposed decision support model is based on the theory of multiatribute utility, through SMARTS technique (Simple Multiattribute Rating Technique using Swings). The application of this model was considered a simple and appropriate tool to the decision problem of outsourcing activities.
\end{abstract}

\section{KEY WORDS}

Outsource, Multicriteria Decision, SMARTS, Support Model for Decision. 


\section{INTRODUÇÃO}

A crescente elevação no nível de competitividade que as empresas enfrentam atualmente exige uma busca constante por alternativas de gestão nos negócios que proporcione a manutenção e a expansão do mercado que disputam. A terceirização de atividades produtivas é uma alternativa de gestão legítima nesta busca por melhores resultados empresariais. A terceirização é tida como uma das mais poderosas ferramentas na administração de recursos (BELCOURT, 2006). De fato, a terceirização vem sendo cada vez mais utilizada como estratégia de produção para obtenção de melhorias no desempenho geral das empresas (QUEROZ, 1998).

O conceito da divisão de trabalho, básico na área de gestão, inspira o uso da terceirização como forma de obtenção de melhores resultados. Entretanto, a divisão de trabalho pregada por Adam Smith teve como ambiente de aplicação os limites da própria empresa. A terceirização, por vezes, ainda que praticada dentro dos limites físicos da empresa contratante, tem sua execução realizada por outra(s) entidade(s) com autonomia e políticas próprias, de modo que não se tem gerência direta da mão de obra envolvida na execução das atividades contratadas.
Existe uma diversidade grande de estudos na literatura preocupados com problemas relacionados à terceirização. Por exemplo, Walker et al. (2006) consideram como administrar mercados desbalanceados (fornecedores demais ou de menos), causados por as decisões de se terceirizar serem tomadas num âmbito local, observando que isto pode prejudicar tanto fornecedores quanto clientes. Vários trabalhos são encontrados na literatura com propostas de modelos de decisão relacionados à terceirização. Wang e Yang (2007) propõem que, para tomar a decisão de terceirizar, devem ser considerados seis fatores: economia, recursos, estratégia, risco, gerência e qualidade. Para solucionar o problema da decisão, ele propõe o uso do AHP (analytic hierarchy process) e do PROMETHEE (Preference Ranking Organization Method for Enrichment Evaluations). O AHP é usado para analisar a estrutura do problema e determinar os pesos dos critérios, e o PROMETHEE é usado para um resultado final mudando os pesos dos critérios em uma análise de sensibilidade. Almeida (2007) apresenta um modelo multicritério para seleção de contratos de terceirização com base no método ELECTRE integrado à teoria da utilidade para solucionar esse tipo de problema, no qual são analisados os custos, a qualidade e o tempo de entrega. Wadhwa e Ravindran (2007) modelam este mesmo problema em um modelo de otimização multi-objetivo, em que um ou mais clientes fazem pedidos para vários fornecedores. Outro modelo proposto por Araz el al (2007) utilizam metodologia multicritério de tomada de decisão para a gerência da terceirização, desenvolvendose um modelo baseado em fuzzy goal programming. Em uma primeira fase, neste modelo, foram determinados os critérios de avaliação e os objetivos, avaliando as terceirizações existentes na empresa através do PROMETHEE. Em uma segunda fase, o modelo desenvolvido seleciona os fornecedores mais adequados à situação e as quantidades de serviços alocadas a estes. O estudo apresentado neste trabalho propõe um modelo de decisão baseado no Método SMARTS, que foi escolhido em função das características próprias do ambiente estudado, mostrando-se uma abordagem adequada ao problema analisado.

Embora a terceirização seja muito empregada, não existem quaisquer garantias de que a estratégia de produção terceirizada traga melhores resultados para a empresa que dela faz uso. Entretanto é fundamental saber quando a terceirização de atividades é, de fato, a alternativa de gestão com melhores chances de sucesso. É exatamente a resposta a essa questão que motivou o desenvolvimento do modelo de apoio à decisão proposto neste artigo. 


\section{ASPECTOS RELEVANTES NA DECISÃO DE TERCEIRIZAR}

Os motivos que levam ao fracasso de uma atividade terceirizada poderiam, em grande parte, ser identificados ainda durante o processo decisório da estratégia produtiva. A escolha desta estratégia de produção envolve diversos aspectos distintos como qualidade, custos, prazos, além dos aspectos legais, organizacionais, políticos e sociais que envolvem uma terceirização. É preciso que o decisor tenha certo grau de conhecimento sobre cada um destes aspectos a fim de fazer os julgamentos necessários para essa tomada de decisão.

\subsection{Aspectos Legais da Terceirização}

Ainda durante o processo decisório, quando está sendo considerada a possibilidade de se terceirizar atividades com parceiros, o conhecimento dos aspectos legais que regulam a prestação de serviços contratados é fundamental para a obtenção dos objetivos que se almejam com essa modalidade de gestão. É nos aspectos legais que residem os maiores riscos para as empresas que transferem suas atividades aos cuidados de terceiros.

A complexidade da legislação trabalhista, o constante aumento dos encargos previdenciários e a situação de desemprego instalada no país foram aos poucos aguçando a criatividade de alguns gestores de empresas, no sentido de utilizar métodos sofisticados, muitos dos quais com o intuito de fugir das obrigações trabalhistas e previdenciárias, passando assim a violar a lei trabalhista de forma indireta. Os procedimentos à margem da lei trabalhista utilizados por empresas, sejam contratantes, contratadas ou ambas e que, infelizmente, não são de ocorrência rara no Brasil, ferem os direitos do trabalhador e colocam em risco a imagem e os resultados das organizações envolvidas no processo. Assim, do ponto de vista do centro decisor de uma organização que julga a possibilidade de terceirizar algumas de suas atividades, espera-se que conheça com profundidade adequada os riscos legais oferecidos por essa modalidade de gestão.

Há muitas críticas à atual legislação trabalhista brasileira, pois, apesar do grande cipoal de leis e sentenças na tentativa de organizar o mercado de trabalho, evitando e resolvendo os conflitos entre patrão e empregado, o que se verifica na prática é um crescimento contínuo dos conflitos trabalhistas, além do crescente número de trabalhadores fora da proteção legal, no mercado informal (PASTORE, 2001).

Políticos, empresários, consultores e a mídia têm falado muito na necessidade de uma reforma na legislação trabalhista. Espera-se que após tal reforma o país possa avançar neste sentido e ganhar maiores condições de competitividade para as empresas nacionais. Entretanto, enquanto isso não ocorre é necessário adaptar-se às regulamentações vigentes do mercado de trabalho.

Embora não exista lei que proíba a terceirização de atividades no Brasil, também ainda não há uma lei específica que regulamente a terceirização e esclareça muitas questões sobre o tema. A preocupação da Justiça do Trabalho com o crescente número de processos de terceirização que envolvem a interposição de empresas, em que muitas vezes se verifica a ocorrência de relações empregatícias camufladas no contrato de terceirização, fraudando a legislação trabalhista, levou o Tribunal Superior do Trabalho (TST) a posicionar-se com relação à questão. Foi proferido então, o entendimento uniformizado por meio do enunciado da Súmula 331, cujo conteúdo revisado em 21/11/2003 é o seguinte:

"Enunciado 331 - Contrato de prestação de serviços - Legalidade - Revisão do Enunciado 256.

I - A contratação de trabalhadores por empresas interposta é ilegal, formando-se o vínculo diretamente com o tomador dos serviços, salvo no caso de trabalho temporário (Lei $n^{\circ}$. 6.019, de 03.01.1974).

II - A contratação irregular do trabalhador, mediante empresa interposta, não gera vínculo de emprego com os órgãos da administração pública direta, indireta ou funcional (art. 37, II, da CF/1988).

III - Não forma vínculo de emprego com o tomador a contratação de serviços de vigilância (Lei nº. 7. 102, de 20.06.1983) e de conservação e limpeza, bem como a de serviços especializados ligados á atividade-meio do tomador, desde que inexistente a pessoalidade e a subordinação direta.

$I V$ - O inadimplemento das obrigações trabalhistas, por parte do empregador, implica a responsabilidade subsidiária do tomador dos serviços, quanto àquelas obrigações, inclusive quanto aos órgãos da administração direta, das autarquias, das fundações públicas, das empresas públicas e das sociedades de economia mista, desde que hajam participado da relação processual e contem também do título executivo judicial (art. 71 da Lei $n^{o}$. 8.666, de 21.06.1993)".

Sobre o escrito do inciso I, Silveira et al. (2008) comentam que é um equívoco aplicar esse inciso ao fenômeno da terceirização, uma vez que, na verdade, ele se refere à contratação de trabalhadores. Como terceirizar significa comprar serviços de forma contínua, e não locar a força do trabalhador, entende-se aqui que não há a presença da terceirização típica. A única hipótese de legalidade da locação de mão de obra é a contratação temporária de trabalhadores, feita normalmente através de empresas que se dedicam a essa atividade, também chamadas de fornecedoras ou locadoras de mão de obra, conforme a Lei N. 6.019/74. 
As disposições contidas no inciso II, da Súmula 331, são específicas para aplicação da terceirização na administração pública. O Estado já foi vítima de severas condenações trabalhistas advindas de processos judiciais movidos por trabalhadores de empresas contratadas pelo poder público. A intenção deste inciso II é, portanto, barrar o ingresso indesejado na carreira pública de trabalhadores de terceiros, ainda que sua contratação ou relacionamento tenham ocorridos de maneira irregular. Essa disposição segue o que determina o inciso II, do art. 37 da Constituição Federal: "A investidura em cargo ou emprego público depende de aprovação prévia em concurso público (...)".

Em relação ao inciso III da Súmula 331, pode-se dizer que, ao contrário dos dois primeiros incisos, que centram sua atenção na intermediação da mão obra, este trata da contratação de serviços. É, portanto nesse inciso que se autoriza a terceirização, ao informar que, em outras palavras, não pode ser considerado empregado do tomador o trabalhador da empresa prestadora de serviços especializados ligados à atividade-meio, desde que realize suas tarefas sem subordinação direta e nem pessoalidade.
A responsabilidade do tomador de serviços é objetiva, conforme a Súmula 331 Inciso IV prescreve que, ocorrendo o inadimplemento das obrigações trabalhistas por parte do empregador, implica na responsabilização subsidiária do tomador. Não se pode admitir que o trabalhador tenha prejuízos com a terceirização. Devem ser resguardados todos os direitos trabalhistas, o que se garante com essa responsabilização do tomador de serviços. Verifica-se, portanto que, em sendo um dos objetivos da terceirização a redução dos custos, pode-se pôr a perder esse alvo por falha na fiscalização dos recolhimentos dos impostos dos trabalhadores da empresa contratada.

Diante de todas as considerações aqui feitas sobre a Súmula 331, que rege a contratação de prestação de serviços, fica muito evidente a necessidade de conduzir um processo de terceirização com segurança, de forma a resultar, de fato, uma melhoria nos resultados, inclusive com uma legítima economia dos tributos. Neste sentido, um contrato de prestação de serviço firmado com a empresa prestadora dos serviços deve prever uma relação de parceria, coberta com todos os cuidados necessários a fim de atingir efetivamente a qualidade e produtividade imprescindível à sobrevivência e ao crescimento dos parceiros.

Uma análise multicritério de apoio à decisão de terceirizar ou não uma determinada atividade só pode ser efetivada depois que se verifica a legalidade de terceirização desta atividade. Em outras

A terceirização de serviços de vigilância e de conservação e limpeza já vem de longa data, sendo praticada pelas empresas e aceita pelo Judiciário trabalhista, não carecendo aqui de maiores comentários. Já o termo "serviços especializados" presente no inciso III carece de comentário. A caracterização dos serviços especializados está calcada na presença dos seguintes requisitos: previsão no contrato social da empresa prestadora, identificação com o objetivo da contratação, execução das atividades com qualificação, autonomia técnica e exigência de certo know-how. Outro termo que merece destaque no inciso III é "atividade-meio". Essa definição tem sido motivo de calorosos debates entres os juristas da área trabalhista. Existe uma enorme dificuldade de se classificar de forma precisa e inequívoca as atividades-meio e as atividades-fim. Para alguns juristas a legalidade ou ilegalidade da prática de compra de serviços terceirizados não está relacionada à natureza do serviço como meio ou fim, e sim à forma como é praticada, verificando-se a existência ou não de fraude aos trabalhadores, ingerência, subordinação, idoneidade econômica do prestador, entre outras situações (SILVEIRA et al., 2008). palavras, o aspecto legal de uma atividade é um critério qualificador, que, sendo satisfeito, habilita a atividade a uma possível terceirização mediante uma avaliação criteriosa dos objetivos que se busca alcançar com essa estratégia de gestão da produção.

\subsection{Parcerias e Objetivos Conflitantes}

O sucesso de uma produção terceirizada está diretamente relacionado com o desempenho do contratado que executa a atividade produtora dos bens ou serviços, objeto da contratação. Diante deste fato, a terceirização estará sempre associada ao estabelecimento de parcerias, que não é uma tarefa simples nem de curto prazo, entretanto é possível estabelecer critérios que indicarão a potencialidade de um candidato a fornecedor vir a tornar-se efetivamente um parceiro da empresa contratante. $\mathrm{O}$ decisor, então, precisa por uma terceirização da produção.

Além da questão da parceria, os objetivos como qualidade, custo e prazo, que se procura em qualquer estratégia produtiva, apresentam conflitos. O conflito do desejo do considerar o importante aspecto da parceria antes de optar 
menor custo e a mais alta qualidade estará sempre presente, sendo que nem sempre é fácil para o decisor estabelecer um equilíbrio adequado entre os vários objetivos conflitantes envolvidos na produção de bens e serviços.

A capacidade humana de análise apresenta limitações quando é necessário levar em consideração, simultaneamente, um número elevado de fatores e elencá-los conforme sua importância dentro de um processo de escolha (MILLER, 1956). Diante de tantos aspectos relevantes a considerar, no intuito de aumentar as chances de acertar a adequada estratégia para as atividades produtivas da empresa, justifica-se a necessidade de um modelo que estruture o problema posto e sirva de apoio para a decisão a ser tomada.

\section{MODELAGEM DE APOIO À DECISÃO}

Para fazer frente à limitação humana de análise surge o Apoio Multicritério a Decisão (AMD), um campo dentro da área de pesquisa operacional onde se reúne um conjunto de métodos aplicados aos problemas de decisão com múltiplos objetivos que se dispõem a auxiliar na sistematização das informações e definições das preferências com relação aos atributos das alternativas avaliadas (GOMES et al., 2006). A escolha de um método específico dependerá de vários fatores, como as características do problema, do contexto considerado, da estrutura de preferências do decisor e da problemática (ALMEIDA, 2003).

A metodologia aplicada no modelo aqui proposto é a técnica SMARTS (Single Measure Rating Technique using Swings), desenvolvida inicialmente em 1971 e posteriormente aprimorada. Essa técnica apresenta-se como uma derivação simplificada da teoria da utilidade multiatributo sendo, portanto, um método compensatório (EDWARDS; BARRON,1994).

As grandes vantagens desta técnica são: a simplicidade de aplicação, a qual potencializa sobremaneira sua utilidade como ferramenta, e a facilidade das questões colocadas para o decisor, que influenciam positivamente o decisor na compreensão e aceitação desta técnica de apoio a sua decisão. Essa característica da facilidade da técnica SMARTS é alcançada mediante algumas simplificações feitas na modelagem do problema. Edwards e Barron (1994) explicam que os possíveis prejuízos originados das simplificações exigidas na modelagem do problema para a aplicação da técnica SMARTS são compensados pelos prováveis erros cometidos no processo de elicitar as preferências em outros métodos. Edwards afirma que os julgamentos de indiferenças requeri- dos por Keeney e Raiffa (1996), entre os pares de alternativas normalmente são difíceis e instáveis. A SMARTS, entretanto não requer que sejam explicitadas preferências ou indiferenças entre as alternativas como exige a maioria dos métodos que derivam do MAUT (Multiple Attribute Utility Theory), tornando com isso o processo mais fácil, claro e amigável para o decisor, além de propiciar uma menor chance de erros no processo decisório devido a uma maior estabilidade das preferências elicitadas.

\section{Ade vários fatores, como as características do problema, do contexto considerado.}

As simplificações necessárias para a aplicação da SMARTS exigem que o modelo decisório atenda a propriedade da linearidade das preferências em todos os atributos e que também atenda a propriedade da independência aditiva, na qual é necessário que se verifique que os valores atribuídos a cada uma das alternativas para um determinado atributo não sejam vinculados aos valores de preferências de outros atributos. Caso as condições de linearidade e independência aditiva não sejam satisfeitas, o método fica conceitualmente comprometido e não pode mais ser considerado logicamente aceitável.

A escolha da técnica SMARTS no modelo proposto para tratar este problema decisório multicritério de terceirizar ou não terceirizar atividades produtivas foi baseada nas seguintes razões:

i) Sua lógica é suficientemente rigorosa e completa para que possa ser aceito como uma ferramenta válida de apoio à decisão;

ii) As propriedades de linearidade e a independência aditiva podem ser alcançadas por aproximação sem prejuízo significativo na representatividade da realidade no modelo utilizado;

iii) A aplicação pelo analista é simples e o decisor tem facilidade para explicitar suas preferências,

iv) A determinação de muitos aspectos envolvidos na terceirização de uma atividade pode ser considerada apenas medianamente dependente de incertezas ambientais, permitindo que as incertezas envolvidas no problema sejam consideradas de forma simplificada, não exigindo nenhum estudo probabilístico da situação.

\subsection{Modelo Proposto}

O modelo aqui proposto parte do pressuposto de que os atores do processo decisório, ou seja, analista, facilitador e 
o centro decisor, foram previamente definidos e que este último não tenha qualquer conflito de interesse relacionado a qualquer das estratégias de produção a ser adotada, garantindo-se com isso um processo isento de tendências. Este centro decisor, que pode ser composto de mais de uma pessoa, será referenciado no modelo proposto simplesmente como decisor e o termo organização se refere à instituição que está aplicando o modelo proposto, a qual o decisor representa.

O modelo proposto é apresentado em bloco na Figura 1, e mostra três estágios distintos. A divisão em estágios permite uma compreensão lógica além de uma menor operacionalização por parte dos atores do processo decisório, como poderá ser constatado no detalhamento do modelo que se segue.

Entrada: A entrada do modelo contém todas as atividades de produção da organização, caso o decisor queira avaliar se a estratégia de produção terceirizada é mais vantajosa para as atuais circunstâncias da organização.

Estágio 1: Neste estágio é verificado se as atividades inseridas no modelo atendem às exigências da legislação. Pode ser requerida aqui a participação de um consultor jurídico a fim de esclarecer a legalidade de determinada atividade produtiva ser executada por terceiros. O critério legal funcionará para o modelo como um filtro onde se admitem apenas as atividades com respaldo legal, passíveis de uma terceirização, e rejeitam-se as atividades sem bases legais, as quais devem ser executada pela própria organização.

Estágio 2: Faz-se neste estágio uma ordenação das atividades legalizadas a fim de se identificarem as atividades com mais vocação à terceirização. Essa ordenação será obtida através de uma análise multicritério pela metodologia SMARTS, em que cada atividade legalizada é avaliada por meio de atributos e então ordenada de modo a evidenciar aquelas atividades produtivas mais vocacionadas para uma possível terceirização. Mediante a lista ordenada de atividades, o decisor pode determinar uma linha de corte, onde a partir de um determinado patamar para baixo as atividades deixarão o modelo e permanecerão sendo executadas diretamente com os próprios recursos da organização. Este corte não é obrigatório, contudo pode ser recomendável a fim de evitar despender muitos recursos no próximo estágio do modelo.

Estágio 3: Neste estágio, através de um segundo processo decisório multicritério, também pela metodologia SMARTS, pode-se ter finalmente a indicação de se a terceirização é a estratégia de produção indicada para uma dada atividade, ou não. O fundamento deste estágio está baseado no fato de que não se pode avaliar o desempenho de uma atividade sem avaliar o executor ou candidato a executor da mesma. Assim, as atividades produtivas até o estágio 2 foram tratadas como alternativas ao problema de decisão colocado, entretanto neste estágio elas deixam de ser alternativas e passam a ser o próprio objeto de estudo do problema. Aqui, cada atividade é submetida individualmente, as alternativas agora são os candidatos a executores da atividade em análise. A elicitação dos valores para cada um dos candidatos a executor nos atributos definidos exigirá a obtenção de muita informação fora da organização. Por ser esta uma tarefa demorada e crítica é que, no estágio anterior, recomenda-se restringir

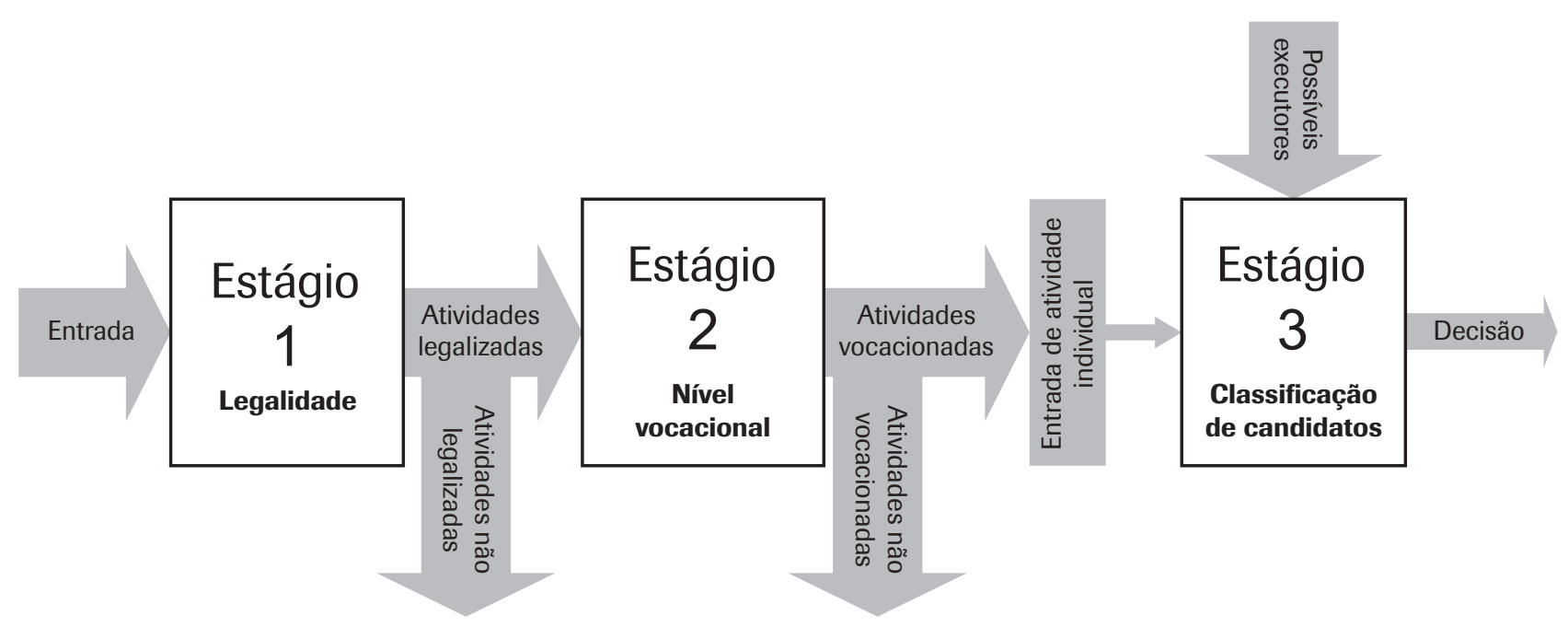

Figura 1: Modelo Proposto - Diagrama em Blocos. 
as atividades submetidas a este último estágio. Como saída deste estágio tem-se, para cada atividade analisada nele, uma lista dos candidatos a executores ordenada pela capacidade de desempenho na realização da atividade. Note-se que neste último estágio olha-se mais para fora da organização, enquanto que no estágio 2 olha-se mais para dentro da própria organização.

A Figura 2 mostra o modelo expandido em estágios e procedimentos. Comenta-se a seguir cada um dos procedimentos do modelo, onde E1P1 significa Estágio1 Procedimento1, e assim por diante.

E1P1 (Estágio 1 / Procedimento 1) - Lista de atividades de interesse para submissão ao modelo proposto: Nesta primeira etapa o decisor faz uma lista de todas as atividades da organização que queira submeter ao modelo proposto. A estratégia da organização é a principal fonte de orientação nesta tarefa.

E1P2 (Estágio 1 / Procedimento 2) - Verificação da legalidade das atividades para terceirização: Pode ser requerido um consultor jurídico a fim de esclarecer a legalidade ou as possibilidades de legalização de determinada atividade produtiva ser executada por terceiros. A legalidade para terceirização é um critério qualificador para esse modelo.

E1D1 (Estágio 1/ Decisão 1) - Decisão da legalidade da terceirização: A decisão neste procedimento é óbvia, e não deve requerer maiores ponderações do decisor. Se a atividade é considerada legal, ela permanece no modelo com chance de uma terceirização, por outro lado, se a atividade não é considerada legal, o modelo já tem uma resposta definitiva para tal atividade, que é executá-la com recursos próprios.

E1R1 (Estágio 1 / Resultado 1) - Lista de atividades passíveis de uma terceirização: Este bloco apenas armazena o resultado obtido da decisão do estágio 1 , não é requerida nenhuma intervenção neste bloco por parte do decisor. Este resultado, ou seja, a lista das atividades elegíveis legalmente para uma terceirização é a matéria-prima do estágio seguinte.

E2P1 (Estágio 2 / Procedimento 1) - Definição dos objetos e critérios para avaliar a vocação das atividades para terceirização: Este procedimento, assim como o procedimento seguinte deste mesmo estágio, é de fato a aplicação de uma metodologia de apoio à decisão multicritério adequada às condições do problema. Para a definição dos atributos e critérios é preciso ter em mente as propriedades de conjunto de atributos de um processo decisório como completude, operacionalidade, independência, ausência de redundância e tamanho máximo. (KEENEY; RAIFFA, 1976) As principais vantagens e desvantagens de um processo de terceirização, seus benefícios, riscos e possíveis consequências, e principalmente a estratégia da empresa conhecida pelo decisor, são as referências básicas para essa discussão a fim de definir uma lista adequada de atributos a ser empregada neste primeiro processo decisório do modelo proposto.

E2P2 (Estágio 2 / Procedimento 2) - Avaliação de alternativas com uso de técnica SMARTS: De posse das alternativas (lista de atividades legalizadas para terceirização) e dos critérios de avaliação é possível obter-se uma priorização destas atividades aplicando-se uma adequada metodologia de apoio de decisão multicritério. O modelo proposto faz uso da técnica SMARTS pelas razões previamente apresentadas. Recomenda-se que seja realizada uma análise de sensibilidade especialmente nos pesos dos critérios para avaliar a estabilidade da solução obtida com a aplicação desta técnica. 


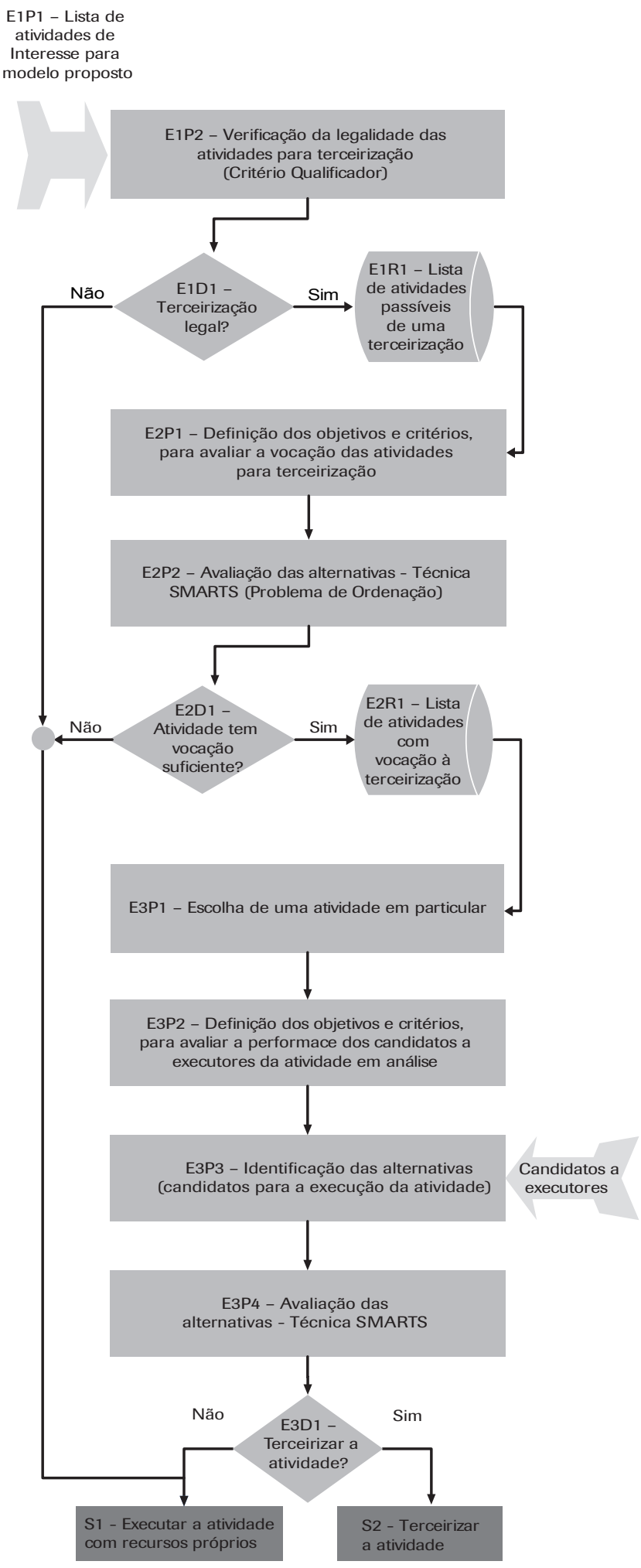

Figura 2: Modelo Proposto para Terceirização de Atividades. candidatos a executores da atividade em análise: Neste procedimento são definidos os objetivos, atributos e critérios da decisão de escolher qual dos candidatos a executores reúne as melhores condições de sucesso na realização da atividade em análise. O modelo proposto sugere a utilização de uma família predefinida de atributos, conforme a Tabela 1 que são básicos e se aplicam a todos os tipos de atividades produtivas (SLACK, 2002).

Para que comparações entre as alternativas possam ser feitas de maneira coerente é necessário que se escolham indicadores de desempenho que medirão cardinalmente os atributos definidos. É necessário que estes indicadores sejam claros e igualmente aplicados a todos os candidatos a fornecedores, inclusive ao setor da própria organização que executa ou poderá executar a atividade em análise.

Alguns atributos não poderão ser efetivamente medidos através dos respectivos indicadores quando não se tem disponível a realização das atividades pelos candidatos. Nestes casos os indicadores serão medidos por experiências passadas ou simulações. Pode-se também usar a medida informada pelo próprio candidato, desde que este se comprometa em cláusula contratual com esta medida, prevendose penalidades compensatórias caso haja descumprimento desse compromisso.

E3P4 (Estágio 3 / Procedimento 4) - Avaliação das alternativas com o uso da técnica SMARTS:

Tem-se aqui a mesma situação do procedimento 2 estágio 2. Mais uma vez faz-se uso da técnica SMARTS pelas mesmas razões já indicadas. Recomenda-se também que seja realizada uma análise de sensibilidade, especialmente nos pesos dos critérios, para avaliar a estabilidade da solução obtida com a aplicação desta técnica.

E3D1 (Estágio 3 / Decisão 1) - Escolha do executor: Como resultado do procedimento anterior tem-se uma lista hierarquizada dos possíveis executores da atividade em análise. Caso a escolha seja por qualquer alternativa que não seja a própria organização, significa evidentemente que a atividade será ou se manterá terceirizada (solução S2). Caso a escolha seja pela execução pela própria organização (solução S1), significa que a atividade não será terceirizada, ou se estiver atualmente terceirizada é recomendado um processo de primeirização.

\section{RESULTADOS DA APLICAÇÃO}

O modelo proposto foi aplicado numa organização que atua no ramo da construção civil. Por se tratar de estudo de cunho estratégico e para evitar problemas com a mão de obra que atualmente executa as atividades em análise, não 
serão revelados aqui o nome da organização e os fornecedores pesquisados, entretanto essa reserva de informação não afeta a verificação da aplicabilidade do modelo. A lista originalmente inserida pelo decisor na entrada do modelo constava de 15 atividades produtivas, conforme a Tabela 2. As atividades serão codificadas a fim de preservar a confidencialidade das futuras estratégias da organização. A Tabela 2 também mostra essa codificação. Afirma-se que a lista das atividades da primeira coluna da Tabela 2 não corresponde à ordem da lista da terceira coluna da mesma tabela.

No primeiro estágio, verificou-se a viabilidade legal de se executar as quinze (15) atividades alistadas por meio da estratégia de produção terceirizada. Todas as atividades foram consideradas legalmente viáveis.

No segundo estágio do modelo, que tem o objetivo de aferir a vocação das atividades para a execução por terceiros, foram realizados muitos debates para finalmente chegar à definição dos atributos de avaliação da vocação. Nestes debates estavam presentes o centro decisor, uma consultoria independente e um facilitador externo. Foi inicialmente utilizada a técnica de "brainstorming". O agrupamento dos atributos sugeridos foi norteado pelos fatores de completude, operacionalidade, independência, ausência de redundância e tamanho máximo, conforme Keeney e Raiffa (1976). Segue abaixo a lista final dos atributos definidos:

i) Impacto da atividade no negócio-fim da organização;

ii) Investimento para executar a atividade com competitividade;

iii) Riscos de transferências de tecnologia;

iv) Nível de dificuldade com a mão de obra própria para a atividade, e:

v) Satisfação com o desempenho atual da atividade.

Após a aplicação da técnica SMARTS obteve-se a ordenação das atividades, segundo a vocação à terceirização conforme a Tabela 3. Em seguida foi feita uma análise de sensibilidade que consistiu na variação dos pesos de cada atributo anteriormente elicitado pelo decisor. Essa alteração nos valores dos pesos foi realizada tanto para mais quanto

Tabela 1: Atributos para escolha de executor da atividade.

\begin{tabular}{cc}
\hline & Atributos \\
\hline 1 & Qualidade \\
2 & Rapidez \\
3 & Credibilidade \\
4 & Flexibilidade \\
5 & Custo \\
\hline
\end{tabular}

para menos da ordem de $10 \%$ (sugerida pelo decisor), sendo realizada apenas para um único atributo de cada vez. A diferença no valor do peso do atributo alterado é compensada nos valores dos pesos dos demais atributos de forma relativa, de modo que a soma dos pesos de todos os atributos continue sendo a unidade. A Tabela 4 mostra as consequências na ordenação das alternativas mediante a variação dos pesos para cada atributo.

\section{contribuição mais significativa deste
modelo é a abordagem desse complexo problema de maneira analítica}

Observa-se que, nesta fase, a problemática de ordenação (GOMES et al., 2006; ALMEIDA; COSTA, 2003) foi vista e entendida pelo decisor como a mais adequada para as suas necessidades de visualização das recomendações do problema em questão. Outras problemáticas, tais como classificação, portfólio (que poderia ser também visualizado como um problema de programação 0-1) e escolha não seriam apropriadas no contexto de decisão estudado. A identificação da problemática mais adequada deve ser efetuada pelo analista junto ao decisor e depende da natureza do problema, bem com do contexto onde a decisão é desenvolvida (ALMEIDA; COSTA, 2003).

Tabela 2: Lista de atividades para submissão ao modelo.

\begin{tabular}{|c|c|c|}
\hline $\begin{array}{l}\text { Lista de atividades em ordem alfabética } \\
\text { para submissão ao modelo }\end{array}$ & & $\begin{array}{c}\text { Lista de } \\
\text { atividades } \\
\text { codificadas }\end{array}$ \\
\hline Administração de frota & & Atividade_1 \\
\hline Análise de viabilidade de projetos & & Atividade_2 \\
\hline Aquisição de imóveis (terrenos) & $\rightarrow$ & Atividade_3 \\
\hline Compras de materiais & $\rightarrow$ & Atividade_4 \\
\hline Contabilidade fiscal e contábil & & Atividade_5 \\
\hline Elaboração de projetos & 元 & Atividade_6 \\
\hline Execução de projetos de instalação & $\frac{\mathbb{O}}{<}$ & Atividade_7 \\
\hline Execução do projeto de infraestrutura & 20 & Atividade_8 \\
\hline Execução do projeto de superestrutura & ల్ర & Atividade_9 \\
\hline Fiscalização de obras & $\overline{0}$ & Atividade_10 \\
\hline Limpeza e conservação & & Atividade_11 \\
\hline Propaganda e marketing & $\vec{\rightarrow}$ & Atividade_12 \\
\hline Relacionamento com clientes (SAC) & $\rightarrow$ & Atividade_13 \\
\hline Segurança patrimonial & & Atividade_14 \\
\hline Sistemas de Informação & & Atividade_15 \\
\hline
\end{tabular}


O decisor considerou a estabilidade da solução suficiente, pois as variações entre o primeiro e segundo colocado na lista não representam neste caso uma preocupação, por se tratar de um problema de ordenação e não de escolha de uma única alternativa. A variação entre as atividades 5 e 6 foi contornada classificando ambas para o próximo estágio da decisão. As demais variações ocorreram em atividades com baixa utilidade relativa (vocação) e não consideradas relevantes. As

Tabela 3: Ordenação de atividades quanto a vocação para terceirização.

\begin{tabular}{ccc}
\hline Classificação & Atividade & Utilidade \\
\hline $1^{\circ}$. & Atividade_10 & 0,775 \\
$2^{\circ}$. & Atividade_12 & 0,772 \\
$3^{\circ}$. & Atividade_9 & 0,731 \\
$4^{\circ}$. & Atividade_7 & 0,532 \\
$5^{\circ}$. & Atividade_6 & 0,503 \\
$6^{\circ}$. & Atividade_11 & 0,497 \\
$7^{\circ}$. & Atividade_2 & 0,43 \\
$8^{\circ}$. & Atividade_15 & 0,386 \\
$9^{\circ}$. & Atividade_13 & 0,316 \\
$10^{\circ}$. & Atividade_14 & 0,304 \\
$11^{\circ}$. & Atividade_5 & 0,316 \\
$12^{\circ}$. & Atividade_8 & 0,246 \\
$13^{\circ}$. & Atividade_4 & 0,211 \\
$14^{\circ}$. & Atividade_3 & 0,167 \\
$15^{\circ}$. & Atividade_1 & 0,044 \\
\hline
\end{tabular}

consequências da análise de sensibilidade relatada na tabela 4 ajudaram o decisor a determinar uma linha de corte para classificar apenas algumas atividades para o próximo estágio do modelo. Foram, então, classificadas pelo decisor apenas 7 (sete) atividades com vocação satisfatória para serem submetidas aos procedimentos do estágio 3 .

No terceiro estágio do modelo, que tem o objetivo de medir o desempenho dos candidatos à execução, são analisadas uma a uma as atividades consideradas com vocação suficiente para uma terceirização, que, neste caso, foram sete (7).

Neste terceiro estágio, foram pesquisados no mercado específico de cada atividade possíveis futuros parceiros que reunissem as condições mínimas predefinidas pelo decisor para executar as atividades em analise. Conforme orientação do decisor, foram procurados e identificados oito possíveis executores externos para cada atividade e, com a própria organização, totalizou nove alternativas a ser avaliada nas suas respectivas atividades. Novamente usou-se a técnica SMARTS, agora com os atributos da tabela 1. Durante o processo de elicitação foi identificado algumas alternativas dominadas que foram substituídas por novas alternativas não dominadas, exceto para a atividade sete (7) que só foi possível identificar 5 candidatos externo com as condições mínimas estabelecidas. Tais condições mínimas variaram conforme a atividade em análise, sendo alguns exemplos destas condições: tempo de existência da empresa, número de funcionários, número de processos trabalhistas, etc.

A primeira atividade a ser submetida ao estágio 3 , foi a atividade dez (10). A escolha do decisor por essa atividade foi óbvia, pois foi a atividade com maior vocação medida. $\mathrm{O}$ resultado da aplicação da metodologia SMARTS para essa

Tabela 4: Análise de sensibilidade da ordenação da vocação das atividades.

\begin{tabular}{|c|c|c|}
\hline \multirow[t]{2}{*}{ Atributo } & \multicolumn{2}{|c|}{ Variação 10\% } \\
\hline & Incremento & Decremento \\
\hline $\begin{array}{l}\text { Impacto da atividade no } \\
\text { negócio-fim da organização }\end{array}$ & Sem alteração na ordenação & $\begin{array}{l}\text { Inversão na ordenação das alternativas } \\
\text { entre a } 10^{\mathrm{a}} \text { e a } 11^{\mathrm{a}} \text { posições }\end{array}$ \\
\hline $\begin{array}{l}\text { Investimento para executar a atividade } \\
\text { com competitividade }\end{array}$ & $\begin{array}{l}\text { Inversão na ordenação das alternativas } \\
\text { entre a } 1^{\mathrm{a}} \text { e a } 2^{\mathrm{a}} \text { posições. }\end{array}$ & $\begin{array}{l}\text { Inversão na ordenação das alternativas } \\
\text { entre a } 9^{\mathrm{a}} \text { e a } 10^{\mathrm{a}} \text { posições }\end{array}$ \\
\hline $\begin{array}{l}\text { Riscos de transferências } \\
\text { de tecnologia }\end{array}$ & $\begin{array}{l}\text { A alternativa na } 9^{\mathrm{a}} \text { posição foi para } \\
11^{\mathrm{a}} \text { posição. As posições } 10^{\mathrm{a}} \text { e } 11^{\mathrm{a}} \\
\text { subiram um posto cada uma }\end{array}$ & $\begin{array}{c}\text { Inversão na ordenação das alternativas } \\
\text { entre a } 5^{\mathrm{a}} \text { e a } 6^{\mathrm{a}} \text { posições }\end{array}$ \\
\hline $\begin{array}{l}\text { Nível de dificuldade com mão de obra } \\
\text { própria para atividade }\end{array}$ & Sem alteração na ordenação & $\begin{array}{c}\text { Inversão na ordenação das alternativas } \\
\text { entre a } 1^{\mathrm{a}} \text { e a } 2^{\mathrm{a}} \text { posições e entre } \\
\text { a } 9^{\mathrm{a}} \text { e a } 10^{\mathrm{a}} \text { posições }\end{array}$ \\
\hline $\begin{array}{l}\text { Satisfação com o desempenho atual } \\
\text { da atividade }\end{array}$ & Sem alteração na ordenação & $\begin{array}{c}\text { Inversão na ordenação das alternativas } \\
\text { entre a } 9^{\text {a }} \text {. e a } 10^{\text {a }} \text {. posições }\end{array}$ \\
\hline
\end{tabular}


atividade é mostrado na tabela 5. Uma vez que a alternativa de maior utilidade é um candidato externo, a indicação do modelo para essa atividade é executá-la com terceiros. Atualmente essa atividade já é executada por um terceiro (Terceirizado A), entretanto o modelo aponta uma possível melhor alternativa de parceria (Terceirizado G) para essa atividade específica. Conclui-se com isso que o modelo também se presta a avaliação de fornecedores.

Neste artigo, está sucintamente reportado apenas o resultado do modelo para três (3) das atividades analisadas. Foram escolhidas as três (3) primeiras atividades segundo a sequência definida pelo decisor. Para o resultado de cada atividade foi realizada uma analise de sensibilidade conforme descrito anteriormente. As análises de sensibilidades realizadas mostraram que as soluções apontadas pelo modelo apresentaram uma boa estabilidade.

Para as três (3) primeiras atividades analisadas foram obtidas as recomendações conforme Tabela 6, onde é mostrado, para cada atividade, a estratégia de produção atualmente em-

\section{Tabela 5: Ordenação dos candidatos a execução da} atividade 10.

\begin{tabular}{ccc}
\hline Ordem & Executor & Utilidade \\
\hline $1^{\circ}$. & Terceirizado G & 0,667 \\
$2^{\circ}$. & Terceirizado A & 0,638 \\
$3^{\circ}$. & Terceirizado D & 0,608 \\
$4^{\circ}$. & Terceirizado B & 0,587 \\
$5^{\circ}$. & Terceirizado C & 0,582 \\
$6^{\circ}$. & Terceirizado F & 0,571 \\
$7^{\circ}$. & Terceirizado H & 0,563 \\
$8^{\circ}$. & Terceirizado E & 0,561 \\
$9^{\circ}$. & Organização & 0,460 \\
\hline
\end{tabular}

pregada, a recomendação do modelo proposto e, finalmente, a decisão tomada pelo decisor.

\section{CONCLUSÃO}

Nas recomendações da aplicação realizada, chama-se atenção para a não indicação de terceirização da atividade 7, embora esta atividade tenha sido considerada bem vocacionada para uma terceirização. A razão para tal fato ocorre justamente porque no estágio 3 olha-se para além dos limites da organização e, neste caso, não foi encontrado no mercado daquela atividade um candidato a executor externo com melhores condições de desempenho que a própria organização. A recomendação da atividade 10 ratificou a estratégia terceirizada como a melhor opção de execução, porém apontou um candidato diferente do parceiro que atualmente realiza esta atividade. Evidenciou-se com isso que o modelo também pode ser aplicado para avaliação de fornecedores de forma comparativa.

O modelo proposto é versátil, podendo ser aplicado para qualquer atividade produtiva, esteja esta sendo atualmente já terceirizada ou não. Os atributos e critérios de cada aplicação do modelo serão sempre consequências diretas da estratégia da organização.

É importante ressaltar que a solução apontada pelo modelo proposto, embora represente as preferências do decisor elicitada no processo, é prescritiva, e não normativa. $\mathrm{O}$ decisor tem total liberdade para revisar, ou até mesmo decidir contrariamente à recomendação do modelo, embora essa última opção exponha uma falta de coerência e racionalidade.

A contribuição mais significativa deste modelo é a abordagem desse complexo problema de maneira analítica, decompondo tal complexidade em partes de simples compreensão, capacitando o decisor a fazer uma escolha com mais segurança e racionalidade no sentido de melhorar os resultados da organização que representa.

Tabela 6: Quadro resumo das recomendações e decisões.

\begin{tabular}{cccc}
\hline & & Atividade Produtiva & \\
\cline { 2 - 4 } & 10 & Não terceirizada & Não terceirizada \\
\hline Estratégia de produção atual & Terceirizada & Terceirizar & Não terceirizar \\
Recomendação do Modelo & Terceirizar, porém com executor \\
diferente do atual & Terceirizar & Não terceirizar \\
Decisão & $\begin{array}{c}\text { Revisar o contrato atual considerando } \\
\text { uma possível troca de fornecedor }\end{array}$ & & \\
\hline
\end{tabular}




\section{Artigo recebido em 26/09/2008 Aprovado para publicação em 26/03/2009}

\section{REFERÊNCIAS}

ALMEIDA, A. T. Multicriteria decision model for outsourcing contracts selection based on utility function and ELECTRE method, Computers \& Operations Research, 34, p. 3569-3574, 2007.

ALMEIDA, A. T. A Utilização de Métodos multicritério de Apoio à decisão. In: ALMEIDA, A. T.; COSTA, A. P. C. Aplicações com Métodos Multicritério de Apoio à Decisão. Recife: Universitária UFPE, p. 1-12, 2003.

ALMEIDA, A. T.; COSTA, A. P. C. Aplicações com Métodos Multicritérios de Apoio à Decisão. Recife: Editora Universitária - UFPE, 2003.

ARAZ, C.; OZFIRAT, P. M.; OZKARAHAN, I. An integrated multicriteria decision-making methodology for outsourcing management, Computers \& Operations Research, 34, p. 37383756, 2007.

BELCOURT, M. Outsourcing - The benefits and the risks. Human Resource Management Review, 16, p. 269-279, 2006.
EDWARDS, W.; BARRON, F. H. SMARTS and SMARTER: Improved Simple Methods for MultiAttribute Utility Measurement. Organizational Behavior and Human Decision Processes, 60, p. 306-325, 1994.

GIOSA, L. A. Terceirização - Uma Abordagem Estratégica, 5. ed. rev. ampl. São Paulo: Pioneira Thomson Learning, 2003.

GOMES, L. F. A.; GOMES, C. F. S.; ALMEIDA, A. T. de. Tomada de Decisão Gerencial: O Enfoque Multicritério, 2. ed. Rio de Janeiro: Ed. Atlas, 2006.

KEENEY, R.; RAIFFA, H. Decision with Multiple objectives: Preferences and Value Trade-offs. John Wiley \& Sons, 1976.

MILLER, G. A. The Magical Number Seven, Plus or Minus Two. The Psychological Review, v. 63, p.123-133, 1956.

PASTORE J. Encargos Sociais: Implicações para o salário, emprego e competitividade. Curitiba: LTr, 2001.
QUEIROZ, C. A. R. de. Manual de Terceirização - onde podemos errar no desenvolvimento e na implantação dos projetos e quais são os caminhos do sucesso. 10. ed. São Paulo: STS, 1998.

SILVEIRA, A. D.; SARAT, N.; MORAES, R. P. Gestão Plena da Terceirização . Rio de Janeiro: Qualimark, 2008.

SLACK, N.; CHAMBERS, S.; JOHNSTON, R. Administração da Produção. 2. ed. São Paulo: Atlas, 2002

WADHWA V.; RAVINDRAN A.R. Vendor selection in outsourcing. Computers \& Operations Research, 34, p. 3725-3737, 2007.

WALKER, H.; KNIGHT L.; HARLAND, C. Outsourced Services and 'Imbalanced' Supply Markets, European Management Journal, 24, p. 95-105, 2006

WANG, J. J.; YANG, D. L. Using a hybrid multicriteria decision aid method for information systems outsourcing. Computers \& Operations Research, 34, p. 3691-3700, 2007.

\section{AGRADECIMENTOS}

Este trabalho foi desenvolvido com apoio parcial do CNPq.

\section{SOBRE OS AUTORES}

\section{Último de Valois}

A.B.I.J.C.S.U.Dias

End. Av. Prof. Francisco Morato, 2430, Caxingui - São-Paulo - SP - 05512-900

Tel.: (11) 3723-3487 Fax: (11) 3723-3581

E-mail: valoisu@gmail.com

\section{Adiel Teixeira de Almeida}

Universidade Federal de Pernambuco

Cx. Postal 7462, Recife - PE - 50630-970

Tel.: (81) 2126-8728 Fax: (81) 2126-7110

E-mail: almeidaatd@gmail.com 